\author{
Alexander Meyenberg \\ David Goldblum \\ Jean-Marc Zingg \\ Angelo Azzi \\ Kalanithi Nesaretnam \\ Monika Kilchenmann \\ Beatrice E. Frueh
}

\section{Tocotrienol inhibits proliferation of human Tenon's fibroblasts in vitro: a comparative study with vitamin E forms and mitomycin C}

Received: 19 November 2004

Revised: 26 January 2005

Accepted: 14 February 2005

Published online: 21 May 2005

(C) Springer-Verlag 2005

\author{
A. Meyenberg - D. Goldblum . \\ M. Kilchenmann · B. E. Frueh $(\bowtie)$ \\ Departement of Ophthalmology, \\ University of Berne, Inselspital Berne, \\ 3010 Berne, Switzerland \\ e-mail: Beatrice.Frueh@insel.ch \\ Tel.: +41-31-6322111 \\ Fax: +41-31-3824779 \\ J.-M. Zingg · A. Azzi \\ Institute for Biochemistry and Molecular \\ Biology, University of Berne, \\ Buehlstrasse 28, \\ 3012 Berne, Switzerland \\ K. Nesaretnam \\ Malaysian Palm Oil Board, \\ PO Box 10620, 50720 \\ Kuala Lumpur, Malaysia
}

\begin{abstract}
Purpose: To evaluate the potential of the vitamin E compound $\alpha$-tocotrienol as antifibrotic agent in vitro. Methods: Using human Tenon's capsule fibroblast cultures, the antiproliferative and cytotoxic effects of the different vitamin $\mathrm{E}$ forms $\alpha$-tocopherol, $\alpha$-tocopheryl acetate, $\alpha$-tocopheryl succinate and $\alpha$-tocotrienol were compared with those of mitomycin C. To mimic subconjunctival and regular oral application in vivo, exposure time of serum-stimulated and serum-restimulated fibroblasts (SF and RF, respectively) to vitamin $\mathrm{E}$ forms was set at 6 days. Cultures were only exposed for $5 \mathrm{~min}$ to mitomycin $\mathrm{C}$ due to its known acute toxicity and to mimic the shorttime intraoperative administration. Proliferation (expressed as \% of control) was determined by DNA content quantification on days 2, 4 and 6, whereas cytotoxicity was assessed by cell morphology and glucose 6-phosphate dehydrogenase (G6PD) release
\end{abstract}

after $24 \mathrm{~h}$. Results: $\alpha$-Tocopherol and $\alpha$-tocopheryl acetate stimulated growth of SF, but not RF. Reduction of fibroblast content by $\alpha$-tocopheryl succinate was accompanied by increased G6PD release and necrosis. Contrary to $\alpha$-tocopheryl succinate, $50 \mu \mathrm{M}$ or repeatedly $20 \mu \mathrm{M}$ of $\alpha$ tocotrienol significantly inhibited proliferation without causing cellular toxicity (maximal effect: $46.8 \%$ ). RF were more sensitive to this effect than SF. Mitomycin C 100-400 $\mu \mathrm{g} / \mathrm{ml}$ showed a stronger antiproliferative effect than $\alpha$-tocotrienol (maximal effect: $13.8 \%$ ). Morphologic characteristics of apoptosis were more commonly found under treatment with mitomycin C. Conclusions: Of the vitamin $\mathrm{E}$ forms tested, only $\alpha$ tocotrienol significantly inhibited growth at non-toxic concentrations. In this in vitro study, antiproliferative effects of mitomycin $C$ were stronger than those of $\alpha$-tocotrienol.

\section{Introduction}

Failure of glaucoma filtration surgery is mostly due to fibrosis of the surgical fistula and the filtering bleb [1, 14]. Fibroblasts from the conjunctival-Tenon's capsule-episcleral interface migrate to the surgical site, proliferate, and secrete extracellular matrix components, ultimately leading to excessive scar formation [14]. Unfortunately, the antiinflammatory and antiproliferative effects of topical steroids are often not sufficient to avoid the induction of this process.
Mitomycin C is currently the most frequently used agent to inhibit this cicatrisation $[18,35]$. However, adjunctive topical chemotherapy with mitomycin $\mathrm{C}$ is associated with severe and potentially sight-threatening complications such as ocular hypotony and endophthalmitis $[15,23,26]$. Cytotoxic effects to various cell types seem to be responsible for these serious side effects [27, 33, 36, 42].

In the search for therapeutic alternatives we focused on vitamin $\mathrm{E}$, the most important lipid-soluble antioxidant in the human body. Vitamin E is a generic name. Tocopherols and tocotrienols represent the two subclasses within the 
vitamin $\mathrm{E}$ family of compounds, both of them consisting of $\alpha-, \beta-, \gamma-$, and $\delta$-isoforms. Esterized forms such as $\alpha-$ tocopheryl acetate or succinate also exhibit vitamin E activity. Lipid-rich plant products and vegetable oils are the main natural sources of vitamin $\mathrm{E}$.

Vitamin E protects biological membranes from oxidation by acting as a radical chain breaking molecule. Important novel neuroprotective [28], antithrombotic [48], antiinflammatory [16], hypocholesterolemic [53], antiatherogenic [46], and antineoplastic effects $[24,32,50]$ of vitamin E cannot all be attributed to the antioxidant activity alone. Increasing evidence suggests involvement of multiple intracellular signaling pathways $[4,19,45]$. It has to be emphasized that the biological functions strongly depend on the vitamin E form applied, and that not all cell types are as susceptible to these effects.

The vitamin $\mathrm{E}$ forms $\alpha$-tocopherol, $\alpha$-tocopheryl acetate and $\alpha$-tocopheryl succinate have been previously tested in in vitro and in animal model studies for potential applications in glaucoma filtration surgery and in the prevention of proliferative vitreoretinopathy $[10,11,20-22,29,37$, $38,40,41]$. However, results were conflicting [30], and there is a need to compare directly the antiproliferative and cytotoxic effects of these different vitamin $\mathrm{E}$ forms with mitomycin $\mathrm{C}$, the gold standard of antiscarring drugs in glaucoma filtration surgery.

$\alpha$-Tocotrienol is one of the major vitamin E compounds in palm oil. Similar to tocopherols, the antiproliferative effects of tocotrienols are mediated by inhibition of protein kinase $C$ [44]. In human and murine tumor cells, tocotrienols induce a cell-cycle arrest in the G-1 phase and apoptosis [54]. To the best of our knowledge, the potential of tocotrienols as antifibrotic agents has not been evaluated.

By using human primary Tenon's capsule fibroblast cultures, we therefore compared the antiproliferative and cytotoxic effects of $\alpha$-tocopherol, $\alpha$-tocopheryl acetate, $\alpha$ tocopheryl succinate, and $\alpha$-tocotrienol with those of mitomycin C.

\section{Materials and methodes}

\section{Reagents}

$\alpha$-Tocopherol (RRR- $\alpha$-tocopherol) was obtained from Cognis (Duesseldorf, Germany), $\alpha$-tocopheryl acetate (dl- $\alpha$-tocopherol acetate) and $\alpha$-tocopheryl succinate ( $\mathrm{d}-\alpha$-tocopherol succinate) were from Supelco (distributed by Fluka Chemie, Buchs, Switzerland). RRR- $\alpha$-Tocotrienol was a kind gift from the Malaysian Palm Oil Board (Kuala Lumpur, Malaysia). Vitamin $\mathrm{E}$ forms were dissolved in ethanol absolute and then stored light-protected at $4^{\circ} \mathrm{C}$. Mitomycin $\mathrm{C}$ (Mitomycin-C Kyowa) was purchased from Kyowa (distributed by Roche Pharma, Reinach, Switzerland) and dissolved freshly in phosphate-buffered saline (PBS) before use.

\section{Cell cultures}

Explants of human Tenon's capsule were obtained from seven patients (aged 68-93 years) at the time of cataract surgery. None of the donors had had antiglaucomatous or antimetabolite treatment, or ocular surgery before. All patients gave their informed consent before inclusion in the study, which was approved by local ethics committee and conformed with the provisions of the Declaration of Helsiniki. The specimens were dissected and placed in $25 \mathrm{~cm}^{2}$ tissue culture flasks containing Dulbecco's minimal essential medium (DMEM) supplemented with L-glutamine $(584 \mathrm{mg} / \mathrm{l})$, sodium pyruvate $(100 \mathrm{mg} / \mathrm{l})$, glucose $(1000 \mathrm{mg} / \mathrm{l})$, penicillin $(60 \mathrm{IU} / \mathrm{ml})$, streptomycin $(60 \mu \mathrm{g} / \mathrm{ml})$ and $10 \%$ fetal calf serum (FCS). Cultures were maintained in a humidified $5 \% \mathrm{CO}_{2}$ incubator at $37^{\circ} \mathrm{C}$. Fibroblasts were characterised morphologically and confluent cultures were trypsinized, centrifuged and repassaged. The above medium was changed twice per week. Quantified by trypan blue dye exclusion method, viability was always more than $95 \%$. For the assays, third- to sixth-passage cells were used.

\section{Cell proliferation assay}

Two experiments were performed with all seven cell lines in triplicate. Substances were either applied to serum-stimulated fibroblasts (SF) in the exponential growth phase, or to previously quiescent serum-restimulated fibroblasts (RF) with a beginning proliferative response. For the experiments with SF and RF, 2000 and 1500 cells/well were seeded in 96-well tissue culture plates (black/clear-bottom, Corning Life Sciences), respectively, each well containing $200 \mu \mathrm{l}$ of culture medium. Preliminary studies showed this difference to be suitable for achieving similar cell densities at the time of compound application. Fibroblasts were then allowed to settle for $24 \mathrm{~h}$ in the incubator.

Growth of serum-stimulated fibroblasts (SF) Cells were rinsed with PBS and fresh DMEM/10\% FCS was added. Vitamin E forms were diluted to the indicated concentrations in above media. To mimic subconjunctival injection and a regular oral vitamin $\mathrm{E}$ supplement intake in vivo, exposure time to all vitamin $\mathrm{E}$ forms was set at 6 days, and application of $\alpha$-tocopherol and $\alpha$-tocotrienol to the cell cultures was repeated at days 2 and 4, respectively. In vivo, the esters $\alpha$-tocopheryl acetate and succinate are naturally cleaved intestinally, resulting in adsorption of the active form $\alpha$-tocopherol. Repeated application was performed by pipetting an identical amount of compounds as initially used into the corresponding wells without changing media. Cells treated with an equivalent amount of ethanol absolute were also included as controls. The cumulative concentration of ethanol was less than $0.6 \%$, which had no effect on 
proliferation and viability (data not shown). Mitomycin C was dissolved in PBS to concentrations of 10, 100, 200 and $400 \mu \mathrm{g} / \mathrm{ml}$. Due to its known acute toxicity and to mimic the short-time intraoperative administration, SF were only exposed for exactly $5 \mathrm{~min}$ to $100 \mu \mathrm{l} /$ well mitomycin C solution. Cells were then gently washed with PBS alone and fed with $200 \mu \mathrm{l} /$ well DMEM/10\% FCS again. Multiple rinsing with PBS was not performed, since a decrease in cell density was observed in preliminary studies. PBStreated cultures served as control. The plates were then incubated for 6 days at $37^{\circ} \mathrm{C}$ in $5 \% \mathrm{CO}_{2}$ in a humidified air atmosphere. No media was changed during this time.

Growth of serum-restimulated fibroblasts (RF) Fibroblasts were washed with PBS $24 \mathrm{~h}$ after plating and incubated for another $48-72 \mathrm{~h}$ with DMEM containing $0.2 \%$ FCS. As previously described [10], this procedure induced growth arrest on human Tenon's capsule fibroblasts in vitro. Cell growth was then restimulated by changing this medium to one containing $10 \%$ FCS. Incubation with vitamin E forms followed as described above. RF were exclusively exposed to $100 \mu \mathrm{g} / \mathrm{ml}$ mitomycin $\mathrm{C}$ due to the almost complete growth inhibition found in the SF experiment at this concentration.

Morphology of SF and RF was studied daily using phase contrast light microscopy (Leica DMIRB research microscope, Leica Microsystems, Wetzlar, Germany). Photomicrographs were obtained with a color camera (Kappa CF15 MC, Kappa Messtechnik, Gleichen, Germany) connected to a video printer (Sony UP-5200MDP, Sony, Schlieren, Switzerland).

Measurement of DNA content A fluorometric assay (CyQUANT Cell Proliferation Assay Kit, Molecular Probes, distributed by JURO Supply, Lucerne, Switzerland) was used to determine cell density on days 2, 4 and 6 by DNA content quantification. Briefly, CyQuant GR dye exhibited green fluorescence enhancement when bound to cellular nucleic acids. Fluorescence due to dye binding to RNA was eliminated by pretreating samples with $4 \mu$ RNase (DNase-free, Roche Diagnostics, Rotkreuz, Switzerland) per $\mathrm{ml}$ cell lysis buffer containing $1 \mathrm{mM}$ ethylenediaminetetraacetate (EDTA). The fluorescent dye and its solutions were always handled light-protected. A reference standard curve was constructed by plotting the fluorescence signal against the DNA content of 50-10,000 human Tenon's capsule fibroblasts/well. The relation was strongly linear (Pearson correlation coefficient $r=0.99$ ). On the indicated days, plates were gently inverted and blotted onto paper towels to remove medium from the wells. Wells were rinsed with PBS, and dry plates were frozen at $-70^{\circ} \mathrm{C}$ for up to 2 weeks. As stated by the manufacturer, the freezing step is important for efficient cell lysis. In order to measure sample fluorescence, plates were thawed, $150 \mu 1$ of cell lysis buffer/ EDTA/RNase was added to each well, and plates were placed for one hour at $37^{\circ} \mathrm{C}$ in $5 \% \mathrm{CO}_{2}$ in a humidified air atmosphere. Next, $50 \mu 1$ of 4 -fold concentrated fluorescent dye/cell lysis buffer/EDTA was added to each well. After light-protected incubation for exactly $31 / 2$ minutes, sample fluorescence was measured with a fluorescence microplate reader (Cytofluor 2300; Millipore, Volketswil, Switzerland) with $485 \mathrm{~nm}$ excitation and $530 \mathrm{~nm}$ emission wave lenghts.

\section{Cytotoxicity assay}

Damaged cells release the cytosolic enzyme glucose 6phosphate dehydrogenase (G6PD) into the surrounding medium. G6PD-release $24 \mathrm{~h}$ after incubation with vitamin $\mathrm{E}$ forms or $24 \mathrm{~h}$ after 5-min exposure to mitomycin $\mathrm{C}$ was determined fluorometrically by the Vybrant Cytotoxicity Assay Kit (Molecular Probes, distributed by JURO Supply, Lucerne, Switzerland). By plotting the fluorescence signal against the G6PD medium content of 500 to 10,000 lysed human Tenon's capsule fibroblasts/well (reference standard curve), a strongly linear relation was observed (Pearson correlation coefficient $r=0.98$ ). Substances containing the fluorescent dye were always processed light-protected. The assay was performed with six different cell lines in triplicate (one cell line was lost due to contamination). In all, 7500 cells/well were seeded to optimise sensitivity of the assay. The further procedure was identical to the proliferation assay with SF until $24 \mathrm{~h}$ after application of the indicated compounds. Tissue culture plates (96-well) were then gently shaken, $50 \mu \mathrm{l}$ medium of each well was transferred to separate plates, and $50 \mu \mathrm{l} /$ well 2-fold concentrated resazurin/reaction mixture was added to the collected media. After light-protected incubation for 20 minutes at $37^{\circ} \mathrm{C}$, measurements were made by using the fluorescence microplate reader with excitation at $530 \mathrm{~nm}$ and emission detection at $590 \mathrm{~nm}$. To determine the maximal G6PD content, all fibroblasts in separate wells were lysed by addition of $1 \mu \mathrm{l}$ 100-fold concentrated cell lysis buffer/well $50 \mathrm{~min}$ before fluorescence measurement. Total cell lysis was checked microscopically.

\section{Statistical analysis}

Results of the proliferation and cytotoxicity assay are presented as mean percentage of control values and mean percentage of total cell lysis values (mean $\pm \mathrm{SD} \%$ ), respectively. Differences between control and compound values were analyzed by Friedman's test followed by the nonparametric Dunnett's test based on rank sum as post hoc analysis. If only a single compound concentration was used in the proliferation assay, results were compared with controls using the Wilcoxon signed-rank test. The criterion for statistical significance was $P<0.05$. 


\section{Results}

Cell proliferation and morphology

Vitamin E forms were dissolved in ethanol absolute, and they all created small lipid droplets on the medium surface after application. $\alpha$-Tocopheryl succinatecs tiny droplets were disappearing first within $24 \mathrm{~h}$, implicating a higher solubility in comparison with the other vitamin $\mathrm{E}$ forms (their bigger droplets were visible for up to $48 \mathrm{~h}$ ). The results of the experiments with continiously growing and restimulated cultures are presented in Fig. 1.

\section{Effect of $\alpha$-tocopherol}

Compared with control cultures, single and multiple application of $\alpha$-tocopherol slightly stimulated growth of SF but not RF. A mild inhibitory effect was only detected on day 4 after twice adding $50 \mu \mathrm{M} \alpha$-tocopherol to RF $(80.0 \pm$ $11.8 \%, P<0.01)$. Cell morphology remained identical to control cultures during the study.

\section{Effect of $\alpha$-tocopheryl acetate}

Growth of continuously growing cultures was markedly promoted by $25-100 \mu \mathrm{M} \alpha$-tocopheryl acetate. Proliferation of restimulated cultures was not affected. No degenerative cell changes were seen in light microscopy.

\section{Effect of $\alpha$-tocopheryl succinate}

$\alpha$-Tocopheryl succinate $12.5 \mu \mathrm{M}$ demonstrated a strong growth stimulating effect in SF cultures (maximal effect: day $4,157.6 \pm 56.6 \%$ ). Again, proliferation of restimulated cultures was not promoted. Higher concentrations of $\alpha$ -
Fig. 1 Effects of incubation with vitamin $\mathrm{E}$ forms for 6 days or exposure to mitomycin $\mathrm{C}$ for $5 \mathrm{~min}$ on human Tenon's fibroblast proliferation. Two experiments were performed: compounds (increasing concentrations upwards) were added to serum-stimulated cells, shown at left, and serum-restimulated previously quiescent cells, shown at right. To mimic regular oral supplement intake in vivo, application of $\alpha$-tocopherol and $\alpha$-tocotrienol was further repeated on days 2 and 4 (concentrations marked with R). A fluorometric assay determined proliferation by DNA content quantification on days 2,4 and 6 . Note the positive $\%$ of control values for both experiments.

Bars with lines represent means; -SD of seven different cell cultures in triplicate. Significant growth inhibiting or stimulating effects, compared with control, are marked with minus and plus, respectively: $\pm P<0.05,--/++$ $P<0.01$

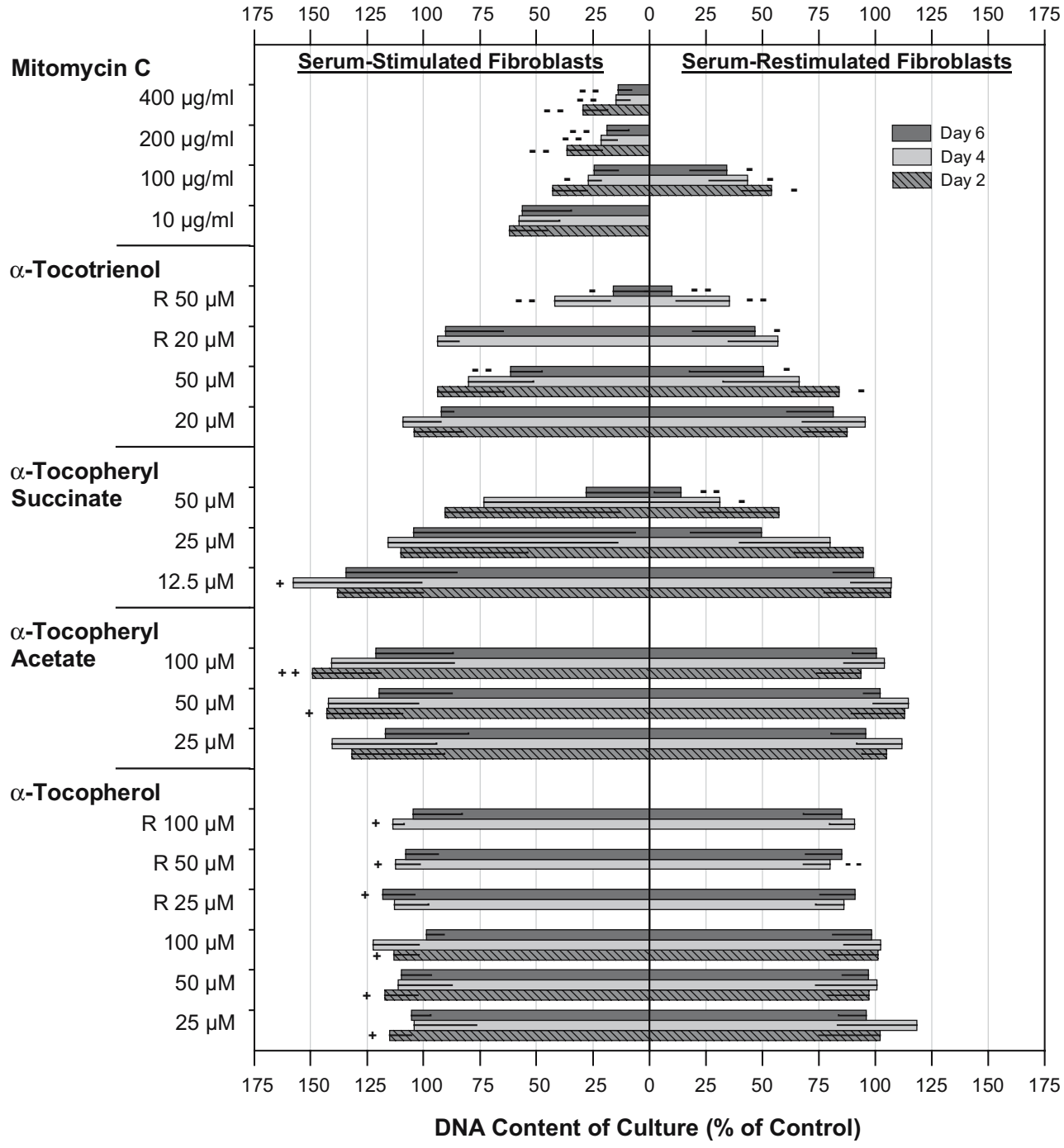


tocopheryl succinate affected cell morphology and viability. Compared to control cultures, fibroblasts exposed to $25 \mu \mathrm{M}$ of $\alpha$-tocopheryl succinate were transiently more granulated between day 2 and 5 (Fig. 2b), accompanied by an increased cell lysate content in the culture media. Severe accumulation of intracytoplasmatic granules was visible after exposure to $50 \mu \mathrm{M} \alpha$-tocopheryl succinate for $24 \mathrm{~h}$. Adherent fibroblasts then retracted their long processes, and became swollen and round shaped (Fig. 2c). The dying cells finally released their content through ruptured plasma membranes into the surrounding culture media. Depending on the ability to adapt to this toxic stress and to delay cell death, the DNA content varied strongly between the seven different fibroblast cultures after incubation with 25 and $50 \mu \mathrm{M}$ of $\alpha$-tocopheryl succinate. On day 6 , the marked decrease of DNA content in RF cultures by $25 \mu \mathrm{M}(49.5 \pm$ $31.2 \%$ ) and SF cultures by $50 \mu \mathrm{M} \alpha$-tocopheryl succinate $(27.9 \pm 34.0 \%)$ was therefore not significant. Nevertheless, the cytotoxic effect of $50 \mu \mathrm{M} \alpha$-tocopheryl succinate was dramatic; necrotic RF cultures showed on day 4 and 6

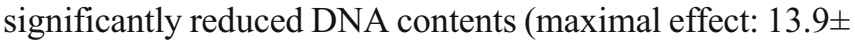
$11.6 \%, P<0.01)$.

\section{Effect of $\alpha$-tocotrienol}

Single application of $50 \mu \mathrm{M} \alpha$-tocotrienol significantly inhibited growth of both stimulated and restimulated cell cultures. This effect was most pronounced on day $6(61.4 \pm$ $14.0 \%$ for $\mathrm{SF}$ and $50.7 \pm 32.8 \%$ for RF, respectively). Further, the DNA content of RF but not of SF cultures was strongly reduced on day 6 after repeated incubation with $20 \mu \mathrm{M} \alpha$-tocotrienol (46.8 $\pm 27.6 \%, P<0.05)$. By phase contrast microscopic observation, no degenerative cell changes were accompanying these antiproliferative effects (Fig. 2d). Cytotoxic effects were only observed after repeated exposure to $50 \mu \mathrm{M}$ of $\alpha$-tocotrienol. After twice adding the compound (day 4), fibroblasts showed increased cytoplas-

Fig. 2 Phase contrast photomicrographs of serum-stimulated human Tenon fibroblasts (SF) on day 4 of the proliferation assay. (a) control; (b) $25 \mu \mathrm{M}$ $\alpha$-tocopheryl succinate; (c) $50 \mu \mathrm{M} \alpha$-tocopheryl succinate; (d) $50 \mu \mathrm{M} \alpha$-tocotrienol; (e) $\mathrm{R}$ $50 \mu \mathrm{M} \alpha$-tocotrienol (application every 2 nd day); (f) $400 \mu \mathrm{g} /$ $\mathrm{ml}$ mitomycin C. Arrows: shrunken degenerated cells. Photographs were obtained from fibroblasts in the center of the well. Magnification: (a), (d), (f) $\times 93$; (b), (c) $,(\mathbf{e}), \times 186$ mic granulation, and some of them did get round shaped (Fig. 2e). The DNA content of continuously proliferating $(41.8 \pm 24.5 \%)$ and restimulated cultures $(35.5 \pm 23.5 \%)$ was markedly decreased $(P<0.01)$, probably partly due to an overlap of antiproliferative and cytotoxic effects. After the third application of $50 \mu \mathrm{M} \alpha$-tocotrienol, overt necrosis as seen during incubation with $50 \mu \mathrm{M} \alpha$-tocopherol succinate developed. Therefore, the DNA content decreased drastically on day 6 in both experiments (SF and RF).

\section{Effect of mitomycin $C$}

Growth of continously proliferating cultures was significantly and strongly inhibited on all DNA measurement days after 5-minute exposure to 200 and $400 \mu \mathrm{g} / \mathrm{ml} \mathrm{mitomycin}$ $\mathrm{C}$, and on day 4 , if treated with $100 \mu \mathrm{g} / \mathrm{ml}$ mitomycin C. The antiproliferative effect of mitomycin $\mathrm{C}$ occurred in a dose-dependent manner (maximal effect: $400 \mu \mathrm{g} / \mathrm{ml}$, day 6 , $13.8 \pm 5.9 \%$ ). After 6 days, only a $17.4 \%$ growth was found in $100 \mu \mathrm{g} / \mathrm{ml}$ mitomycin C treated SF cultures. RF were therefore exclusively exposed to this antimetabolite concentration. Restimulated cultures were then significantly inhibited by $100 \mu \mathrm{g} / \mathrm{ml}$ mitomycin $\mathrm{C}$ on all measurement days (maximal effect: day 6, 34.2 $\pm 16.2 \%$ ).

No degenerative cell changes were seen in fibroblast cultures exposed to mitomycin $\mathrm{C}$ concentrations as high as $200 \mu \mathrm{g} / \mathrm{ml}$. However, 5-minute treatment with $400 \mu \mathrm{g} / \mathrm{ml}$ mitomycin $\mathrm{C}$ resulted in a steady decrease of the absolute DNA content over the 6 day observation period (mean difference between day 0 and 6: $-33.3 \%$ ). Induction of apoptosis by $400 \mu \mathrm{g} / \mathrm{ml}$ mitomycin $\mathrm{C}$ was assumed, as its morphologic characteristics like nuclear and cytoplasmic condensation, and nuclear fragmentation were observed more often than in control cultures. In contrast to the cytotoxic effects of $\alpha$-tocopherol succinate $(50 \mu \mathrm{M})$ and $\alpha$ tocotrienol (repeatedly $50 \mu \mathrm{M}$ ), which affected to a varying degree virtually all cells, most fibroblasts remaining after
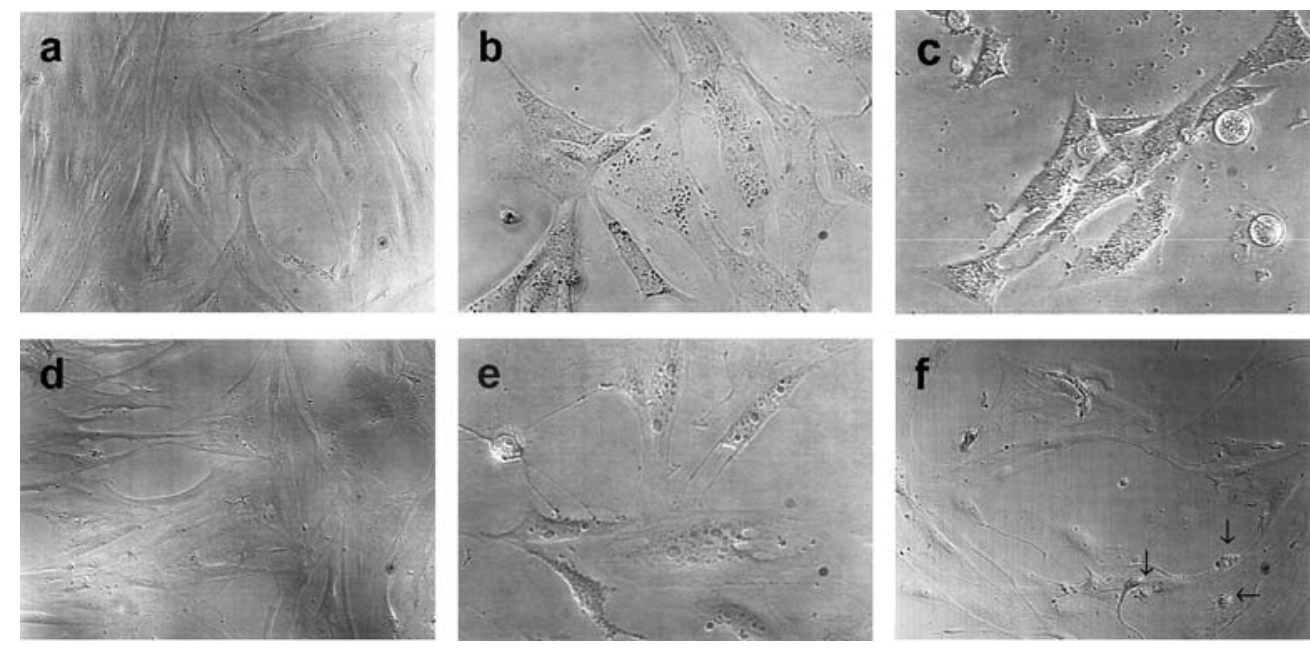
treatment with $400 \mu \mathrm{g} / \mathrm{ml}$ mitomycin $\mathrm{C}$ showed normal morphologic features (Fig. 2f).

In general, the anti-/proliferative response to vitamin $\mathrm{E}$ forms differed between continuously proliferating and restimulated fibroblast cultures. RF cultures seemed to be more susceptible to antiproliferative effects, whereas growth stimulating effects were only observed in SF cultures. To summarize the results of the proliferation assay, $50 \mu \mathrm{M}$ and repeatedly $20 \mu \mathrm{M}$ of $\alpha$-tocotrienol were the only vitamin $\mathrm{E}$ forms/concentrations proving a relevant inhibitory effect without affecting cell morphology and viability. The antiproliferative effect of $100-400 \mu \mathrm{g} / \mathrm{ml}$ mitomycin $C$ was stronger and earlier apparent, compared with $\alpha$-tocotrienol.

Glucose 6-phosphate dehydrogenase release

Accumulation of intracytoplasmatic granules was observed already $24 \mathrm{~h}$ after incubation with $50 \mu \mathrm{M} \alpha$-tocopherol succinate. To evaluate for early cytoplasmic membran rupture, the G6PD release into the culture media was measured

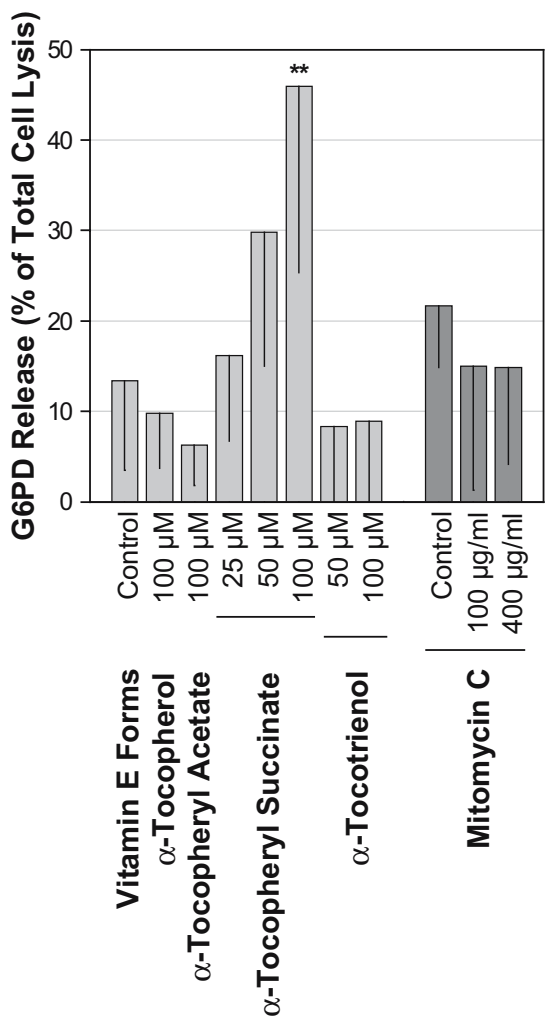

Fig. 3 Relative glucose 6-phosphate dehydrogenase (G6PD) culture media levels $24 \mathrm{~h}$ after incubation with vitamin $\mathrm{E}$ forms and 5-min exposure to mitomycin C. Dying cells release G6PD through ruptured cytoplasmic membranes. Note that $100 \mu \mathrm{M} \alpha$-tocopheryl succinate and $100 \mu \mathrm{M} \alpha$-tocotrienol were double the concentrations used in the proliferation assay. Data are presented as \% of total cell lysis. Bars with lines indicate means; -SD of six different cell cultures in triplicate. Significant differences, compared with control, are marked with $* * P<0.01$
$24 \mathrm{~h}$ after incubation with vitamin $\mathrm{E}$ forms or 5-min exposure to mitomycin C (Fig. 3).

Since dysmorphic cell changes were found from day 4 on after twice adding $50 \mu \mathrm{M}$ of $\alpha$-tocotrienol, $100 \mu \mathrm{M}$ of the compound was additionally tested to correspond with maximum drug accumulation. This was confronted with the effect of $100 \mu \mathrm{M} \alpha$-tocopherol succinate on G6PD release.

Of the vitamin E forms, only $50 \mu \mathrm{M}(29.8 \pm 14.8 \%$ of total cell lysis) and $100 \mu \mathrm{M}$ of $\alpha$-tocopheryl succinate (46.0 $\pm 26 \%$ of total cell lysis, $P<0.01$ ) showed increased G6PD culture medium levels, compared to controls (13.4 \pm $10.0 \%$ of total cell lysis). Due to the extended handling procedure with a possible negative effect on cell viability, G6PD culture media concentration in PBS treated wells (control of mitomycin $\mathrm{C}$ ) was higher than in vitamin $\mathrm{E}$ control. G6PD levels of 100 and $400 \mu \mathrm{g} / \mathrm{ml}$ mitomycin C were not increased in comparison with controls.

\section{Discussion}

A comparison between tocopherol and mitomycin $\mathrm{C}$ has been reported previously [11]. In the present study, $\alpha$ tocotrienol and additional vitamin $\mathrm{E}$ forms were compared with mitomycin $\mathrm{C}$, based on their effects on proliferation, morphology and viability of cultured human Tenon's capsule fibroblasts. The study did not account for the effects on cell migration, attachment and contraction, collagen synthesis and angiogenesis, which are further critical steps involved in surgical bleb failure. No cultures of eyes with increased risk of trabeculectomy failure, such as young age or long-term use of topical anti-glaucomatous drugs, were included in this study.

$\alpha$-Tocopherol inhibits proliferation by reducing protein kinase $\mathrm{C}$ activation, independent of its antioxidant properties $[4,45]$. By adsorbing this lipophilic compound to FCS [5], our group previously found a strong antiproliferative effect on restimulated human Tenon's capsule fibroblasts and retinal pigment epithelium cells [10,29]. Other authors dissolved vitamin $\mathrm{E}$ in ethanol to inhibit growth of similar cell types $[38,40]$. In the present study, we used ethanol for reasons of comparability. Instead of inhibiting proliferation, both $\alpha$-tocopherol and $\alpha$-tocopheryl acetate then stimulated growth (SF cultures), or had no effect on proliferation (RF cultures). The former could be explained by the removal of lipoperoxide-induced inhibition of growth. Higher concentrations than $100 \mu \mathrm{M}$ were not tested, since $\alpha$-tocopherol becomes water-insoluble and precipitates in the form of micellar aggregates in vivo. As compound and cell type were identical in our present and previous study, the different carrier substances (ethanol versus FCS) might have contributed to the conflicting results to a great extent. Lipid droplets on the culture medium surface indicated inhomogenous distribution of the vitamin $\mathrm{E}$ forms previously dissolved in ethanol. Prolonged exposure to oxygen and 
heat might have inactivated a considerable amount of the compounds prior to cellular uptake.

Together with dietary fat, all unesterized vitamin $\mathrm{E}$ forms are directly absorbed in the human intestine. $\alpha$-Tocopheryl acetate and succinate are naturally cleaved intestinally, resulting in adsorption of the active form $\alpha$-tocopherol. Only $\alpha$-tocotrienol and $\alpha$-tocopherol were therefore repeatedly applied to the cultures to mimic a regular oral vitamin E supplement intake in vivo. However, an unpredicted accumulation of vitamin E could not be fully excluded, since the relation of oxidative loss and uptake into the cells remained unknown.

$\alpha$-Tocopheryl succinate induces differentiation, DNA synthesis arrest, or apoptosis in malignant cells, but not in most normal cell lines [39]. Involvement of transforming growth factor $\beta$-, Fas-, and c-Jun- $\mathrm{NH}_{2}$-terminal kinase signaling pathways is suggested [3]. In the years 1999 and 2000, Larrosa, Pinilla and colleagues published in vitro, animal model and histologic studies evaluating the potential application of $\alpha$-tocopheryl succinate and acetate in glaucoma surgery $[21,22,37,38]$. Both compounds injected subconjunctivally improved the outcome of glaucoma filtration surgery in rabbits. In our in vitro study, any possible antiproliferative effect of $\alpha$-tocopheryl succinate was strongly overlaid by its cytotoxic effects. Increased cytoplasmic granulation, cell swelling, and early plasma membrane leakage strongly pointed to simple primary necrosis [17]. In vivo, simple primary necrosis leads to inflammation of surrounding tissue. Other authors exposing ocular cell types and tissues to comparable concentrations of $\alpha$-tocopheryl succinate (up to $100 \mu \mathrm{M}$ ) did not report relevant cytotoxic effects $[9,38,40,41]$. No major complications were reported in a rabbit model of glaucoma filtration surgery with adjunctive topical $\alpha$-tocopheryl succinate and acetate therapy [22, 37].

In our study, $\alpha$-tocotrienol was the only vitamin $\mathrm{E}$ form showing a relevant inhibitory effect on both serum-stimulated and -restimulated fibroblasts in the absence of cytotoxicity. By using $50 \mu \mathrm{M}$ or repeatedly $20 \mu \mathrm{M}$ of $\alpha$ tocotrienol, a roughly $50 \%$ growth inhibition was achieved after 4-6 days of incubation. Restimulated cultures were more sensitive to this effect. We therefore conclude that $\alpha$ tocotrienol better inhibits activation of fibroblasts than ongoing proliferation. Antiproliferative effects of higher $\alpha$ tocotrienol concentrations or $\gamma-/ \delta$-isoforms were not tested, but they might be even stronger [25].

Toxic effects of $\alpha$-tocotrienol were only observed from day 4 on after twice exposing cultures to $50 \mu \mathrm{M}$ of the compound. In contrast to $\alpha$-tocopheryl succinate, G6PD levels after incubation with $100 \mu \mathrm{M} \alpha$-tocotrienol were not increased. Due to the different onset of degenerative changes, the tolerability and the mechanisms of the cytotoxic effects seem not to be identical for both substances.

Considering the possible administration routes of $\alpha$-tocotrienol in patients, subconjunctival injection or intraoperative topical application seems favorable since sufficiently high tissue concentrations can be assumed. Penetration of tocotrienols through skin and of instilled $\alpha$-tocopheryl acetate into the anterior chamber and lens has been shown in animal models $[31,47]$. No toxic intraocular effects of $\alpha$-tocotrienol are known.

Vitamin E supplements to human diet are considered to be safe. Caution is required in cases of regular aspirin intake or in patients with vitamin $\mathrm{K}$ deficiency, as the risk of bleeding is increased by vitamin E. No significant adverse effects were reported in studies of long-time daily supplementation of human individuals with palm oil tocotrienol $[46,49,51,52]$. No teratogenic potential is known. However, it is remains unclear if appropriate concentrations of $\alpha$-tocotrienol $(25-50 \mu \mathrm{M}$ in this study) can be achieved at the surgical site after systemic medication. $\alpha$ Tocopherol was shown to predominantly accumulate in the retina after oral supplementation, compared with other ocular tissues [2, 43]. Plasma concentrations of $\alpha$-tocotrienol only increased from less than $1 \mu \mathrm{M}$ to approximately $8 \mu \mathrm{M}$ in humans supplemented with a palm oil concentrate [52]. However, accumulation of $\alpha$-tocotrienol in many solid organs/tissues is well known. $\alpha$-Tocotrienol concentrations in the skin and adipose tissue can be tenfold to those in the plasma $[12,13,34]$.

Induction of apoptotic cell death in human Tenon's capsule fibroblasts after 5-min exposure to $400 \mu \mathrm{g} / \mathrm{ml}$ mitomycin $\mathrm{C}$ has been described by Crowston and colleagues $[6,7]$. After 6 days, $27 \%$ of the fibroblasts were reported to exhibit morphologic characteristics of apoptosis [6]. Under very similar conditions, we detected a comparable cell content decrease by $33 \%$ and morphologic alterations such as nuclear and cytoplasmic condensation, indicating an apoptotic effect of $400 \mu \mathrm{g} / \mathrm{ml}$ mitomycin C. It should be noted that the methods applied prove cell death, but not its mechanism.

Apoptosis has been shown to be physiologically involved in scar formation [8]. As apoptosis does in general not provoke an inflammatory reponse in vivo [17], death of fibrolasts and inflammatory cells by apoptosis should be an acceptable event in the postoperative period, leading to reduction of scar tissue. However, complications such as bleb leak and infection may occur if the bleb tissue is too extensively devitalized.

Comparing $\alpha$-tocotrienol and mitomycin $\mathrm{C}$, fibroblast proliferation was earlier and stronger inhibited after 5-min exposure to the antimetabolite. Almost complete growth inhibition of SF cultures was achieved by using $100 \mu \mathrm{g} / \mathrm{ml}$ mitomycin $\mathrm{C}$. Furthermore, mitomycin $\mathrm{C}$ induced growth arrest is irreversible based on its DNA alkylating properties. As $\alpha$-tocotrienol regulates the activity of cytosolic enzymes, its antiproliferative effect is not likely to last for a long time after medication is discontinued. However, mitomycin $\mathrm{C}$ induced toxicity to ocular structures is well known. Alternative drugs with a reversible antiproliferative effect may be advantageous in wound healing situations where the healing stimulus is maximal only during a short 
period that can be covered by treatment. Due to the different antiproliferative mechanisms, a synergistic effect of $\alpha$ tocotrienol and mitomycin $\mathrm{C}$ is further conceivable, potentially allowing lower mitomycin $\mathrm{C}$ concentrations and shorter exposure-time to increase drug safety. Our findings suggest that $\alpha$-tocotrienol deserves further evaluation in animal model studies to clarify its impact on the outcome of filtering procedures.
Acknowledgements The authors thank Milko E. Iliev, MD, for helpful discussions and critical comments on the manuscript.

Financial interests: A. Meyenberg, none; D. Goldblum, none; J.-M. Zingg, none; A. Azzi, none; K. Nesaretnam, employee of the Malaysian Palm Oil Board, no proprietary interests; M. Kilchenmann, none; B. E. Frueh, none.

The authors have full control of all primary data and they agree to allow Graefe's Archive for Clinical and Experimental Ophthalmology to review their data if requested.

\section{References}

1. Addicks EM, Quigley HA, Green WR, Robin AL (1983) Histologic characteristics of filtering blebs in glaucomatous eyes. Arch Ophthalmol 101:795-798

2. Alvarez RA, Liou GI, Fong SL, Bridges CD (1987) Levels of alphaand gamma-tocopherol in human eyes: evaluation of possible role of IRBP in intraocular alpha-tocopherol transport. Am J Clin Nutr 46:481-487

3. Anderson K, Simmons-Menchaca M, Lawson KA, Atkinson J, Sanders BG, Kline K (2004) Differential response of human ovarian cancer cells to induction of apoptosis by vitamin E succinate and vitamin $\mathrm{E}$ analogue, alpha-TEA. Cancer Res 64:4263-4269

4. Boscoboinik D, Szewczyk A, Hensey C, Azzi A (1991) Inhibition of cell proliferation by alpha-tocopherol. Role of protein kinase C. J Biol Chem 266:6188-6194

5. Chan AC, Tran K (1990) The uptake of $\alpha$-tocopherol by human endothelial cells in culture. Lipids 25:17-21

6. Crowston JG, Akbar AN, Constable PH, Occleston NL, Daniels JT, Khaw PT (1998) Antimetabolite-induced apoptosis in Tenon's capsule fibroblasts. Invest Ophthalmol Vis Sci 39:449-454

7. Crowston JG, Chang LH, Constable PH, Daniels JT, Akbar AN, Khaw PT (2002) Apoptosis gene expression and death receptor signaling in mitomycin$\mathrm{C}$ treated human tenon capsule fibroblasts. Invest Ophthalmol Vis Sci 43:692-699

8. Desmouliere A, Redard M, Darby I, Gabbiani G (1995) Apoptosis mediates the decrease in cellularity during the transition between granulation tissue and scar. Am J Pathol 146:56-66

9. Fallor MK, Silverman CA, Yoshizumi MO (1994) Ocular toxicity of experimental intravitreal vitamin E. J Toxicol 3:337-345
10. Haas AL, Boscoboinik D, Mojon DS, Bohnke M, Azzi A (1996) Vitamin E inhibits proliferation of human Tenon's capsule fibroblasts in vitro. Ophthalmic Res 28:171-175

11. Haas AL, Boscoboinik DO, Bohnke M (1996) Inhibition of Tenon fibroblast proliferation. Comparison between tocopherol and mitomycin-C. Invest Ophthalmol Vis Sci 37(suppl):877S

12. Hayes KC, Pronczuk A, Liang JS (1993) Differences in the plasma transport and tissue concentrations of tocopherols and tocotrienols: observations in humans and hamsters. Proc Soc Exp Biol Med 202:353-359

13. Ikeda S, Tohyama T, Yoshimura H, Hamamura K, Abe K, Yamashita K (2003) Dietary alpha-tocopherol decreases alpha-tocotrienol but not gamma-tocotrienol concentration in rats. J Nutr 133:428-434

14. Jampel HD, McGuigan LJ, Dunkelberger GR, Hernault NL, Quigley HA (1988) Cellular proliferation after experimental glaucoma filtration surgery. Arch Ophthalmol 106:89-94

15. Jampel HD, Pasquale LR, Dibernardo C (1992) Hypotony maculopathy following trabeculectomy with mitomycin C. Arch Ophthalmol 110:1049-1050

16. Jiang Q, Ames BN (2003) Gammatocopherol, but not alpha-tocopherol, decreases proinflammatory eicosanoids and inflammation damage in rats. FASEB J 17:816-822

17. Kanduc D, Mittelman A, Serpico R et al (2002) Cell death: apoptosis versus necrosis. Int J Oncol 21:165-170

18. Kitazawa Y, Kawase K, Matsushita H, Minobe M (1991) Trabeculectomy with mitomycin: a comparison study with fluorouracil. Arch Ophthalmol 109:1693-1698

19. Kline K, Yu W, Sanders BG (2001) Vitamin E: mechanisms of action as tumor cell growth inhibitors. J Nutr 131:161-163

20. Larrosa JM, Veloso AA Jr, Leong FL, Refojo MF (1997) Antiproliferative effect of intravitreal alpha-tocopherol and alpha-tocopheryl-acid-succinate in a rabbit model of PVR. Curr Eye Res 16:1030-1035
21. Larrosa JM, Polo V, Ramirez T, Pinilla I, Pablo LE, Honrubia FM (2000) Alpha-tocopherol derivatives and wound healing in an experimental model of filtering surgery. Ophthalmic Surg Lasers 31:131-135

22. Larrosa JM, Polo V, Ramirez T et al. (2000) Histopathological evaluation of vitamin $\mathrm{E}$ in surgical fistula closure. Arch Soc Esp Oftalmol 75:523-528

23. Lehmann OJ, Bunce C, Matheson MM et al. (2000) Risk factors for development of post-trabeculectomy endophthalmitis. Br J Ophthalmol 84:1349-1353

24. Malafa MP, Fokum FD, Mowlavi A, Abusief M, King M (2002) Vitamin E inhibits melanoma growth in mice. Surgery 131:85-91

25. McIntyre BS, Briski KP, Gapor A, Sylvester PW (2000) Antiproliferative and apoptotic effects of tocopherols and tocotrienols on preneoplastic and neoplastic mouse mammary epithelial cells. Proc Soc Exp Biol Med 224:292301

26. Membrey WL, Poinoosawmy DP, Bunce C, Hitchings RA (2000) Glaucoma surgery with or without adjunctive antiproliferatives in normal tension glaucoma: 1 intraocular pressure control and complications. Br J Ophthalmol 84:586-590

27. Mietz H, Addicks K, Diestelhorst M, Kriegelstein GK (1994) Extraocular application of mitomycin $\mathrm{C}$ in a rabbit model: cytotoxic effects on the ciliary body and epithelium. Ophthalmic Surg 25:204-244

28. Mishima K, Tanaka T, Pu F et al (2003) Vitamin $\mathrm{E}$ isoforms alpha-tocotrienol and gamma-tocopherol prevent cerebral infarction in mice. Neurosci Lett 337:56-60

29. Mojon D, Boscoboinik D, Haas A, Bohnke M, Azzi A (1994) Vitamin E inhibits retinal pigment epithelium cell proliferation in vitro. Ophthalmic Res 26:304-309 
30. Mojon D, Boscoboinik D, Haas A, Bohnke M, Azzi A (1997) Inhibition of bovine RPE cells by vitamin E succinate (comment). Graefes Arch Clin Exp Ophthalmol 235:190-191

31. Nagata M, Kawazu K, Midori Y, Kojima M, Shirasawa E, Sasaki K (2001) Intracameral and lenticular penetration of locally applied stable isotope-labeled vitamin E. Jpn J Ophthalmol 45:125-127

32. Nesaretnam K, Guthrie N, Chambers AF, Carroll KK (1995) Effect of tocotrienols on the growth of a human breast cancer cell line in culture. Lipids 30:1139-1143

33. Nuyts RM, Pels E, Greve EL (1992) The effects of 5-fluorouracil and mitomycin $\mathrm{C}$ on the corneal endothelium. Curr Eye Res 11:565-570

34. Ohrvall M, Tengblad S, Vessby B (1994) Tocopherol concentrations in adipose tissue. Relationships of tocopherol concentrations and fatty acid composition in serum in a reference population of Swedish men and women. Eur J Clin Nutr 48:212-218

35. Palmer SS (1991) Mitomycin as adjunct chemotherapy with trabeculectomy. Ophthalmology 98:317-321

36. Park HK, Lee KW, Choi JS, Joo CK (2002) Mitomycin C-induced cell death in mouse lens epithelial cells. Ophthalmic Res 34:213-219

37. Pinilla I, Larrosa JM, Polo V, Honrubia FM (1999) Alpha-tocopherol derivatives in an experimental model of filtering surgery. Ophthalmic Res 31:440-445

38. Pinilla I, Piazuelo E, Jimenez P et al (2000) Inhibitory effect of alpha tocopherol succinate on fibroblast wound healing. Arch Soc Esp Oftalmol 75:383-388
39. Prasad KN, Kumar B, Yan XD, Hanson AJ, Cole WC (2003) Alpha-tocopheryl succinate, the most effective form of vitamin $\mathrm{E}$ for adjuvant cancer treatment: a review. J Am Coll Nutr 22:108-117

40. Sakamoto T, Hinton DR, Kimura H, Spee C, Gopalakrishna R, Ryan SJ (1996) Vitamin E succinate inhibits proliferation and migration of retinal pigment epithelial cells in vitro: therapeutic implication for proliferative vitreoretinopathy. Graefes Arch Clin Exp Ophthalmol 234:186-192

41. Sakamoto T, Oshima Y, Ishibashi T, Inomata H (1996) Inhibitory effect of Vitamin E succinate on the proliferation of cultured bovine choroidal endothelial cells. J Jpn Ophthalmol Soci 100:777-782

42. Smith S, D'Amore PA, Dreyer EB (1994) Comparative toxicity of mitomycin $\mathrm{C}$ and 5-fluorouracil in vitro. Am J Ophthalmol 118:332-337

43. Stephens RJ, Negi DS, Short SM, van Kuijk FJ, Dratz EA, Thomas DW (1988) Vitamin E distribution in ocular tissues following long-term dietary depletion and supplementation as determined by microdissection and chromatography-mass spectrometry. Exp Eye Res 47:237-245

44. Sylvester PW, McIntyre BS, Gapor A, Briski KP (2001) Vitamin E inhibition of normal mammary epithelial cell growth is associated with a reduction in protein kinase C(alpha) activation. Cell Prolif 34:347-357

45. Tasinato A, Boscoboinik D, Bartoli GM, Maroni P, Azzi A (1995) d- $\alpha-$ Tocopherol inhibiton of vascular smooth muscle cell proliferation occurs at physiological concentrations, correlates with protein kinase $\mathrm{C}$ inhibition, and is independent of its antioxidant properties. Proc Natl Acad Sci USA 92:12190-12194

46. Tomeo AC, Geller M, Watkins TR, Gapor A, Bierenbaum ML (1995) Antioxidant effects of tocotrienols in patients with hyperlipidemia and carotid stenosis. Lipids 30:1179-1183
47. Traber MG, Rallis M, Podda M, Weber C, Maibach HI, Packer L (1998) Penetration and distribution of alpha-tocopherol, alpha- or gamma-tocotrienols applied individually onto murine skin. Lipids 33:87-91

48. Unchern S, Laoharuangpanya N, Phumala N et al. (2003) The effects of vitamin $\mathrm{E}$ on platelet activity in beta-thalassaemia patients. $\mathrm{Br} \mathbf{J}$ Haematol 123:738-744

49. Wahlqvist ML, Krivokuca-Bogetic Z, Lo CS, Hage H, Smith R, Lukito W (1992) Differential serum responses of tocopherols and tocotrienols during vitamin supplementation in hypercholesterolaemic individuals without changes in coronary risk factors. Nutr Res 12(suppl):181S-201S

50. Wu K, Shan YJ, Zhao Y, Yu JW, Liu BH (2001) Inhibitory effects of RRRalpha-tocopheryl succinate on benzo(a) pyrene $(\mathrm{B}(\mathrm{a}) \mathrm{P})$-induced forestomach carcinogenesis in female mice. World $\mathrm{J}$ Gastroenterol 7:60-65

51. Qureshi AA, Qureshi N, Wright JJ et al. (1991) Lowering of serum cholesterol in hypercholesterolemic humans by tocotrienols (palmvitee). Am J Clin Nutr 53(suppl):1021S-1026S

52. Qureshi AA, Bradlow BA, Brace L et al. (1995) Response of hypercholesterolemic subjects to administration of tocotrienols. Lipids 30:1171-1177

53. Qureshi AA, Sami SA, Salser WA, Khan FA (2002) Dose-dependent suppression of serum cholesterol by tocotrienol-rich fraction (TRF25) of rice bran in hypercholesterolemic humans. Atherosclerosis 161:199-207

54. Yu W, Simmonss-Menchaca M, Gapor A, Sanders BG, Kline K (1999) Induction of apoptosis in human breast cancer cells by tocopherols and tocotrienols. Nutr Cancer 33:26-32 